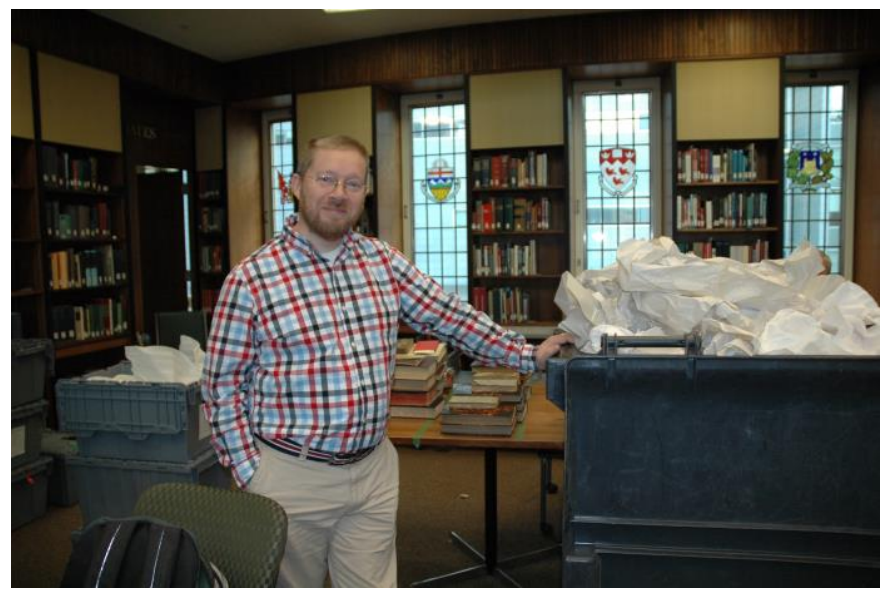

\title{
Profile: Martin Morris
}

Life Sciences Liaison Librarian McGill University Montreal, Quebec

\section{Describe your early background:}

I'm from the UK and came to live in Canada in 2011 - my partner and I are eagerly awaiting the date of our Canadian citizenship test as I write.

After getting my BSc in Chemistry from the University of Wales, I worked as a PA and then as a techie moving from PCs and small networks to system administration for server farms; I continue to have a strong interest in technology. My interest in politics led me to be very active in election campaign organisation, combined with a 7-year spell as a city councillor in St Albans (a city north of London).

I had wanted to retrain as a librarian for many years and finally made the jump when I started my MSc in 2006 as a distance-learning student at Robert Gordon University, while at the same time working for Hertfordshire Public Libraries as a library assistant. I'll confess that the transition was challenging at times! I graduated in 2009 shortly after starting my first professional librarian post.

\section{What (or who) influenced you to pursue a career in libraries?}

My initial motivation was to a certain extent political, springing from my conviction that people need access to reliable and unbiased information in order to make good and informed decisions - I felt that I had skills and a way of thinking that would fit a librarian. While this has become more nuanced over the few years I have been a librarian, it remains the core of what I find valuable about the role.

Despite the regular demands that we justify our existence and the necessity or value of the work we do, libraries and librarians do make a difference, and I enjoy being a small part of that difference.

\section{Where are you working now, and what do you like best about your current job?}

I'm a life sciences liaison librarian at McGill University in Montreal. It's pretty much my dream job: it fits very well with my natural interest in sciences; I find it enormously intellectually stimulating, and there are endless opportunities to learn. I particularly enjoy the experience of learning about a new area of medicine when beginning a systematic 
review collaboration as this often means that I get to be taught about that area by people who are leaders in their field. I also value the opportunities to conduct my own research and collaborating with my colleagues-l'm currently working on getting my first manuscript published and learning about the peer-review process.

\section{What is your most memorable library experience?}

Being an academic librarian has encouraged me to develop my public speaking, teaching, and presentation skills. I've been known to get pretty bad stage fright before big presentations or new courses, but this has gone down over time as I get more experience. Over the summer I was fortunate enough to be selected to give two presentations at IFLA —on both occasions co-presenting with a supportive colleague. Being able to deliver these with the minimum of stage fright was certainly memorable for me!

\section{What do you do for fun?}

My partner and I are both big language lovers and really enjoy learning new languages (or at least trying) as well as experiencing other parts of the world. In fact, those are two big reasons why we decided to come to live in Montreal. I also really enjoy playing with computers and am currently digitising a library catalogue for a small organisation here. Other hobbies include learning the cello, very slowly, and keeping fish.

\section{Tell us about an interesting book you've read recently. What appealed to you about it?}

Because of my strong interest in constructed languages (I learned Esperanto when I was sixteen and still use it today), I recently read Arika Okrent's In the Land of Invented Languages. The book covers the history of Esperanto, Volapük, Loglan and other languages and very skillfully describes how constructed language projects often fit the social and cultural norms of their time, while at the same time demonstrating more universal qualities such as the human need to perfect and improve. I make it sound a little heavy, but it was actually an engrossing and undemanding read. Recommended!

\section{What accomplishment are you most proud of?}

Successfully emigrating from the UK to Canada while also making the switch from public to academic libraries. Both were a big jump, but I am so happy that we went ahead anyway.

\section{What issues do you think will have a big impact on libraries in the next few years?}

Clearly, the Internet and electronic resources continue to have a major and long-lasting impact on libraries. I'd like to point out a different change within health librarianship 
which l've noticed: the increasing involvement of medical librarians in areas traditionally outside our role.

Typically, when collaborating on a research synthesis such as a systematic review, librarians will be involved only in the earlier stages-the creation of search strategies and retrieval of results. Later stages, including the appraisal of evidence, are usually left to the medical professionals. In recent years, a small body of literature has been published showing that this distinction is becoming less rigid as more librarians learn about medical statistics and the appraisal of clinical evidence.

I believe that this change is likely to become more and more established as medical librarians move into new roles and could have a significant impact on medical librarianship as a whole.

\section{If you had one chance to time travel, when would you travel to and why?}

lain M Banks' brilliant books about the Culture, set in the distant future, include fun descriptions of artificial intelligence. I'd love to be able to spend just a day in that period to see how humanity and Als have developed and whether they end up being very similar in character or diverge over time. It would also be fun to see how language develops. 